\title{
HOLOSALENIA BAHIENSIS, UM NOVO EQUINÓIDE (ECHINODERMATA) DO ALBIANO DA BACIA DE CAMAMU, BRASIL
}

\author{
CYNTHIA LARA DE CASTRO MANSO \\ Universidade Federal de Sergipe, Campus Universitário Prof. Alberto Carvalho, Av. Vereador Olimpio Grande s/n, \\ Itabaiana, SE, Brasil.cynthia@phoenix.org.br \\ WAGNER SOUZA-LIMA \\ Fundação Paleontológica Phoenix, Rua Geraldo Menezes de Carvalho, 218, 49050-750, Aracaju, SE, Brasil. \\ wagner@phoenix.org.br
}

\begin{abstract}
RESUMO - No presente trabalho é descrita uma nova espécie de equinóide do gênero Holosalenia Smith \& Wright, proveniente da bacia de Camamu, sul do Estado da Bahia, Brasil. O material estudado foi coletado nos calcarenitos bioclásticos do membro Germânia da formação Algodões, aflorantes em diversos pontos nas ilhas de Cangaíba e Boipeba Estas rochas são posicionadas no Albiano superior com base na presença do amonóide Elobiceras bahiensis Maury, descrito de rochas semelhantes encontradas mais ao sul. As características diagnósticas de Holosalenia bahiensis sp.n. incluem: o sistema apical arredondado com as placas lisas e pouco demarcadas; as depressões suturais pequenas ou ausentes; as placas elevadas em torno do periprocto. O formato globular da carapaça e a ausência de pódios respiratórios especializados na região aboral, sugerem que $H$. bahiensis n. sp., teria sido epifaunal em um ambiente protegido, abaixo da influência de ondas. O peristoma levemente invaginado sugere um tipo de alimentação variada obtida sobre substrato mole.
\end{abstract}

Palavras-chave: Holosalenia bahiensis, Echinoidea, Cretáceo, Albiano, bacia de Camamu.

\begin{abstract}
HOLOSALENIA BAHIENSIS, A NEW ECHINOID (ECHINODERMATA) FROM ALBIAN OF THE CAMAMU BASIN, BRAZIL. A new echinoid species of the genus Holosalenia Smith \& Wright is described from Camamu Basin, southern Bahia State, Brazil. The specimens were collected in the bioclastic calcarenite from the Germânia Member of Algodões Formation, which crops out in many points of the Cangaíba and Boipeba islands. These rocks are attributed to the Upper Albian on basis of the presence of the ammonite Elobiceras bahiensis Maury, described from similar rocks found further south. The diagnostics features of Holosalenia bahiensis sp.n. include: apical disc rounded with smooth plates; sutures hardly or not visible; small or absent sutural depressions; and the periproct surrounded by a high ridge. The globular test lacking aboral specialized respiratory tube-feet suggests that $H$. bahiensis sp.n. would have been epifaunal in a protected subtidal environment, below active normal wave influence. The gently invaginated peristome suggests a kind of alimentation epifaunal generalist on soft substratum.
\end{abstract}

Key words: Holosalenia bahiensis, Echinoidea, Cretaceous, Albian, Camamu Basin.

\section{INTRODUÇÃO}

O gênero Holosalenia foi proposto por Smith \& Wright (1990) durante o trabalho de revisão taxonômica e filogenética dos Calicyna. Este gênero é representado por um pequeno grupo de quatro espécies de equinóides as quais teriam vivido nos mares do Cretáceo (Cenomaniano e Campaniano/ Maastrichtiano) da Europa, África e Oriente Médio, não incluindo até o momento nenhuma espécie sul-americana. As espécies de Holosalenia agrupadas por Smith \& Wright
(1990), possuem em comum um círculo escrobicular completo situado ao redor dos tubérculos primários, carapaças com oito ou mais placas interambulacrais em uma coluna, um pequeno disco apical, no qual as suturas triplas são pouco desenvolvidas ou ausentes, e tubérculos ambulacrais primários não contíguos, envolvidos por uma série de grânulos. No presente trabalho é descrita e figurada uma nova espécie para o gênero Holosalenia proveniente da bacia de Camamu, coletados em calcarenitos bioclásticos e dolomitos do Membro Germânia da Formação Algodões. 
Equinóides saleniídeos foram assinalados pela primeira vez na bacia de Camamu por Santos (1958), que examinou fragmentos de moldes internos e externos de exemplares provenientes da ilha de Cangaíba (baía de Camamu) identificando-os como Salenia. Brito (1964), examinou estes e outros espécimes coletados na ilha de Boipeba (baía de Camamu), e atribuiu-os à espécie Salenia sergipensis White, descrita para a bacia de Sergipe-Alagoas, no Estado de Sergipe. Em seu trabalho Brito (1964:5) afirma "que os tubérculos secundários apresentam-se mal conservados" não tendo, portanto observado uma das principais características diagnósticas deste grupo. Smith \& Bengston (1991) examinando os exemplares da bacia de Camamu, identificados por Brito (1964) como Salenia sergipensis White, concluíram que os mesmos deveriam ser referidos ao gênero Holosalenia (Smith \& Wright, 1990).

\section{CONTEXTO GEOLÓGICO}

A bacia de Camamu, sob o ponto de vista estrutural, estende-se desde a falha de Itapuã ao norte, em Salvador, que a separa da bacia de Sergipe-Alagoas, até o Alto do Itacaré, ao sul, que constitui seu limite com a bacia do Almada. O limite com a bacia do Recôncavo ocorre através da falha da
Barra. A seção marinha da bacia de Camamu está representada pelas Formações Taipus-Mirim, Algodões, Urucutuca, Caravelas e Rio Doce, com deposição iniciada a partir do Neo-Aptiano (Souza-Lima et al., 2003).

$\mathrm{Na}$ bacia de Camamu a Formação Algodões aflora nas ilhas de Tinharé, Boipeba, Tatu, Germânia, Quiepe, ilha Grande de Camamu, ilha de Cangaíba e em diversos pontos da península de Maraú. As localidades onde foram coletados os equinóides podem ser observadas nas Figuras 1 e 2.

A Formação Algodões compreende uma sucessão de calcários marinhos que totalizam entre 40 e $180 \mathrm{~m}$ de espessura, sobrepostos à Formação Taipus-Mirim e cobertos pela Formação Urucutuca, na região submersa da bacia. A Formação Algodões, de idade neo-albiana a turoniana (Souza-Lima et al., 2003; Andrade et al., 2006), está dividida nos membros Germânia e Quiepe. O Membro Germânia é constituído por calcarenitos e calciruditos oolíticos/oncolíticos, parcialmente dolomitizados e, mais raramente, silicificados na borda da bacia. O Membro Quiepe é caracterizado por calcilutitos e folhelhos carbonáticos (Figura 3).

A idade neo-albiana da Formação Algodões, na área de estudo, está baseada na presença do amonóide Elobiceras bahiensis Maury, 1925, descrito da localidade de Algodões, situada na região sul desta área.

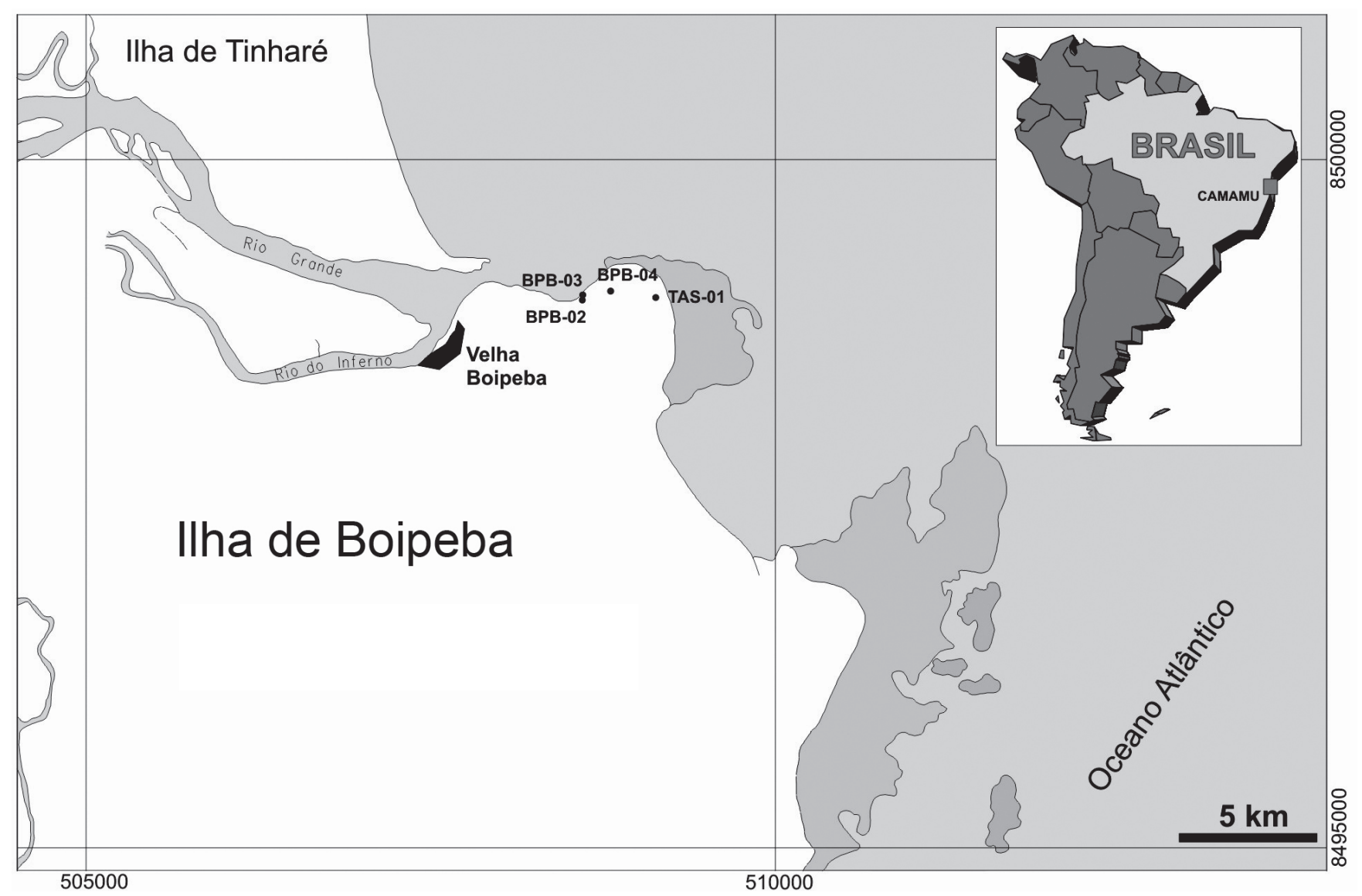

Figura 1. Mapa de localização dos afloramentos na llha de Boipeba, Baía de Camamu, Bahia.

Figure 1. Location map of the outcrops in Boipeba Island, Camamu Bay, Bahia. 


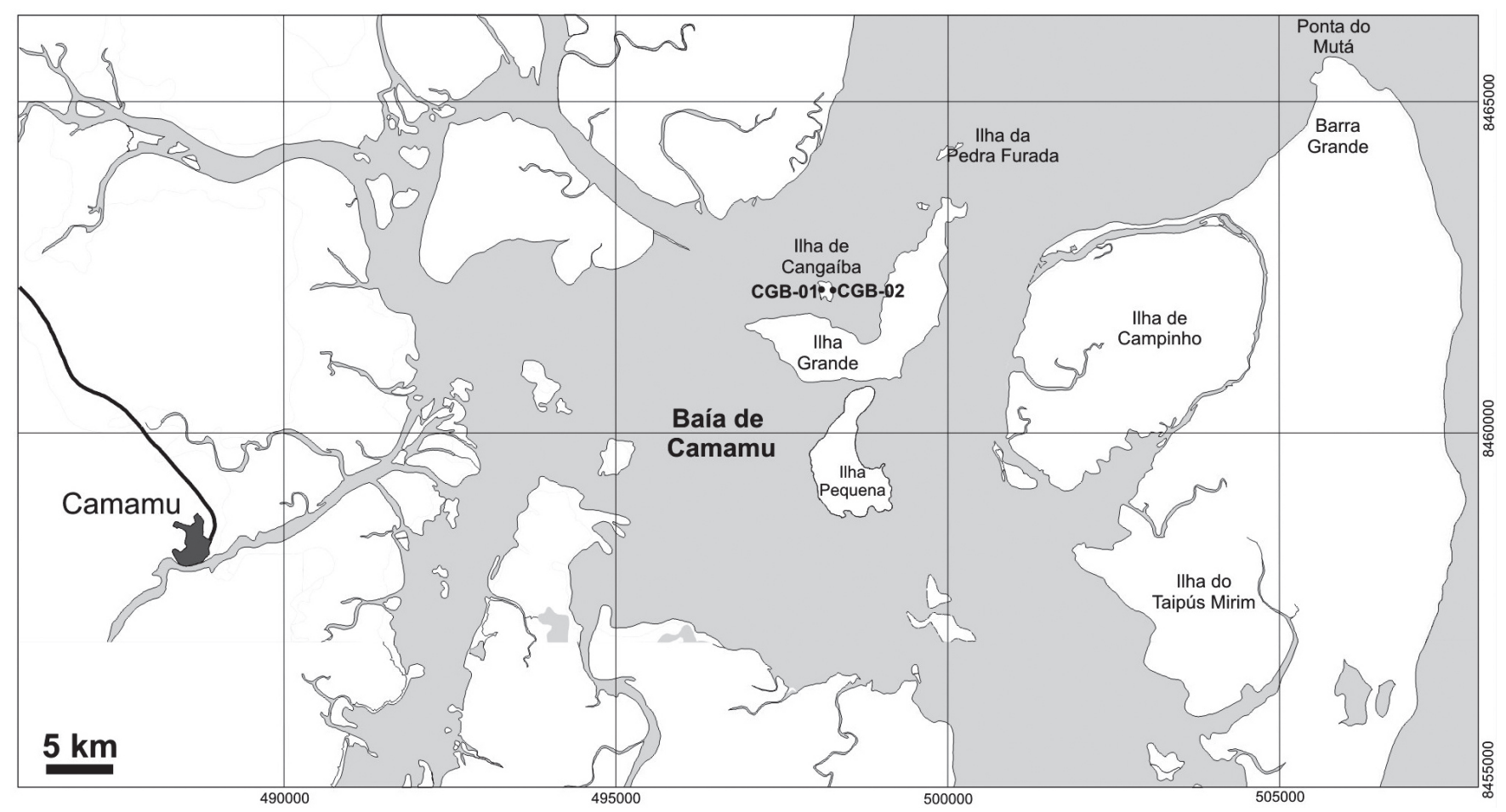

Figura 2. Mapa de localização dos afloramentos na llha de Cangaíba, Baía de Camamu, Bahia. Figure 2. Location map of the outcrops in Cangaíba Island, Camamu Bay, Bahia.

\section{MATERIAL E MÉTODOS}

Os fósseis aqui estudados são provenientes de afloramentos da Formação Algodões, localizados nas ilhas de Boipeba e Cangaíba, litoral centro-sul do Estado da Bahia, e estão depositados na coleção da Fundação Paleontológica Phoenix (FPH), em Aracaju, e na coleção de invertebrados do Museu Nacional (MN) no Rio de Janeiro. Após a preparação dos espécimes, foram levantados os dados biométricos. O espécime fóssil em melhor estado de preservação foi designado como holótipo e os demais como parátipos. As interpretações paleoecológicas basearam-se na análise morfológica da carapaça, segundo Smith (1995) e discutidas por Manso (2003).

A metodologia utilizada nas descrições dos afloramentos, segue Bengtson (1983), adotada para a bacia de Sergipe. As coordenadas foram obtidas utilizando-se um GPS sobre o datum Córrego Alegre, convertidas para o datum Aratu e arredondadas para os 50 metros mais próximos. As coordenadas UTM estão referenciadas ao meridiano central $39^{\circ}$. As seguintes terminologias são adotadas: a sigla Kagg significa Cretáceo, Formação Algodões, Membro Germânia; "exposição" significa um afloramento com altura inferior a 0,5 m e o termo "seção" define um afloramento com altura superior a $0,5 \mathrm{~m}$.

As localidades descritas a seguir, na ilha de Boipeba são de fácil acesso, localizadas na linha de praia do litoral nordeste da ilha, enquanto aquelas da ilha de Cangaíba só podem ser acessadas na maré baixa.

Boipeba. Referências à área em Brito (1964, 1967, 1981).
Boipeba 2 (BPB-02). UTM 8.499.000N/508.600E. Mapa topográfico folha: SD-24-X-C-IV-1-NO Velha Boipeba.

Seção em colina com face voltada para $\mathrm{N}$ e grandes blocos e fragmentos ao longo da costa nordeste da ilha de Boipeba, próximo à vila de Velha Boipeba. Altitude 0-4m. Kagg: Calcarenito creme-claro, fino a médio, bioclástico, dolomitizado, localmente sacaroidal a vugular, fossilífero, com equinóides e moluscos bivalves (Neithea).

Boipeba 3 (BPB-03). UTM 8.499.000N/508.600E. Mapa topográfico folha: SD-24-X-C-IV-1-NO Velha Boipeba.

Seção em colina com face voltada para $\mathrm{N}$ e grandes blocos $\mathrm{e}$ fragmentos ao longo da costa nordeste da ilha de Boipeba, próximo à vila de Velha Boipeba. Altitude 0-3m. Kagg: Calcarenito creme-claro, fino a médio, bioclástico, dolomitizado, localmente sacaroidal a vugular, fossilífero, com equinóides e moluscos bivalves (Neithea).

Boipeba 4 (BPB-04). UTM 8.499.050N/508.800E. Mapa topográfico folha: SD-24-X-C-IV-1-NO Velha Boipeba.

Seção em colina com face voltada para NE e grandes blocos e fragmentos ao longo da costa nordeste da ilha de Boipeba, próximo à vila de Velha Boipeba. Altitude 0-3m. Kagg: Calcarenito creme-claro, fino a médio, bioclástico, dolomitizado, localmente sacaroidal a vugular, fossilífero, com equinóides e moluscos bivalves (Neithea).

Cangaíba. Referências à área em Santos (1958) e Brito (1967). Cangaíba 1(CGB-01). UTM 8.462.150N/498.100E. Mapa topográfico folha: SD-24-V-D-VI-4-SE Camamu.

Blocos e fragmentos expostos em planície de maré com esparsa vegetação de mangue na ilha de Cangaíba, baía de 


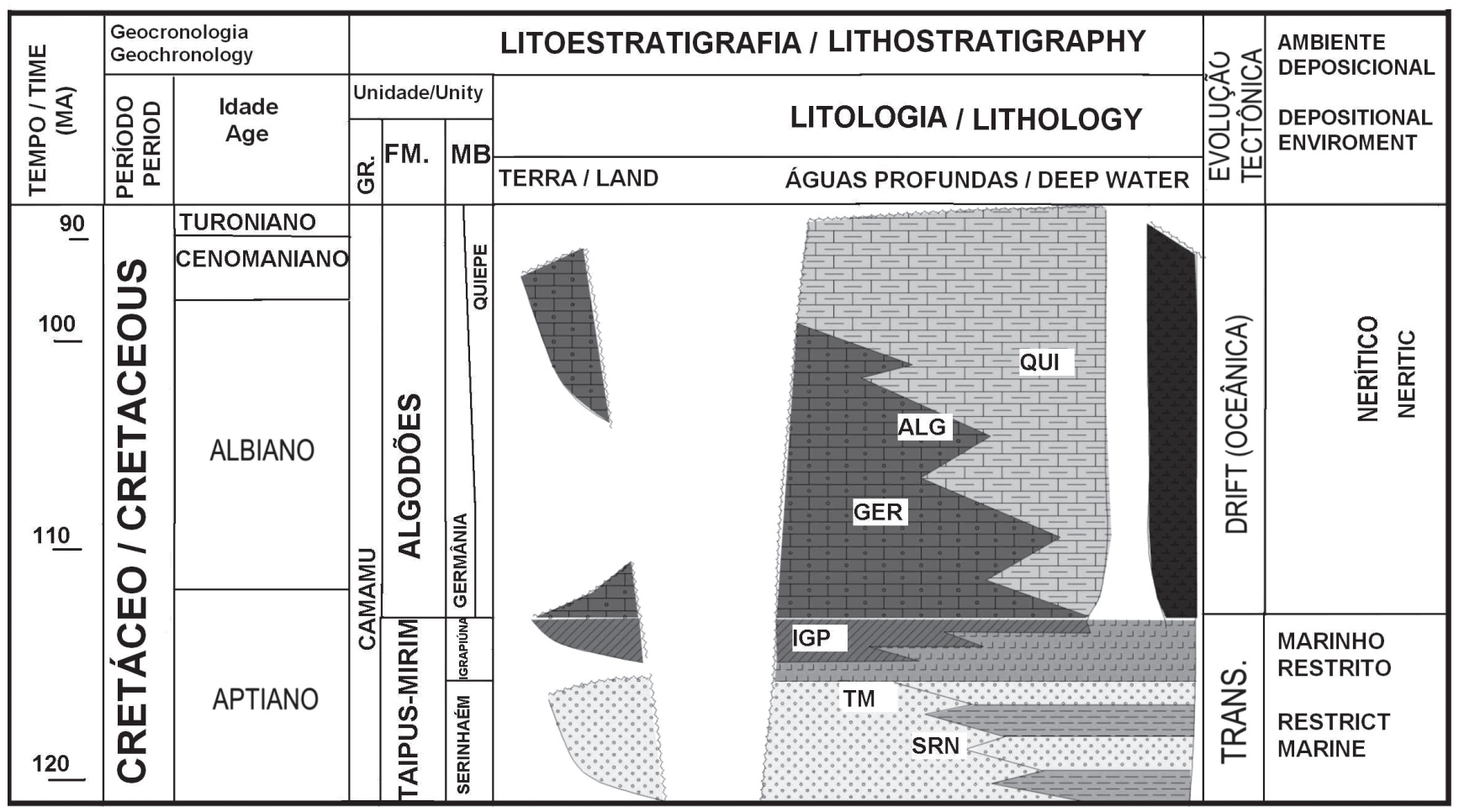

Figura 3. Carta estratigráfica da seção marinha Aptiana-Albiana da Formação Algodões (Netto et al.,1995). Abreviaturas: ALG, Formação Algodões; GER, Membro Germânia; IGP, Membro Igrapiúna; QUI, Membro Quiepe; SRN, Membro Serinhaém;TM, Formação Taipus-Mirim.

Figure 3. Stratigraphic chart of the Aptian-Albian marine section from the Camamu Basin (Netto et al.,1995). Abbreviations: ALG, Algodões Formation; GER, Germânia Member; IGP, Igrapiúna Member; QUI, Quiepe Member; SRN, Serinhaém Member; TM, Taipus-Mirim Formation.

Camamu. Altitude 0 m. Kagg: calcarenito creme a cinza-claro, fino a médio, bioclástico, localmente fossilífero, parcialmente dolomitizado, localmente sacaroidal e vugular.

Cangaíba 2(CGB-02). UTM 8.462.150N/498.250E. Mapa topográfico folha: SD-24-V-D-VI-4-SE Camamu.

Seção em pequena encosta com face voltada para norte e fragmentos dispersos na planície de maré no litoral NE da ilha de Cangaíba, na baía de Camamu. Altitude 0-1 m. Kagg: Calcarenito bioclástico creme, parcialmente dolomitizado, localmente sacaroidal/vugular, fossilífero.

Tassimirim 1 (TAS-01). UTM 8.499.000N/509.150E. Mapa topográfico folha: SD-24-X-C-IV-1-NO Velha Boipeba.

Blocos e fragmentos ao longo da costa nordeste da ilha de Boipeba, na praia de Tassimirim. Altitude 0-1 m. Kagg: Calcarenito creme claro, fino a médio, dolomitizado, localmente sacaroidal/vugular, pouco fossilífero com presença de equinóides e moluscos bivalves (Neithea).

\section{SISTEMÁTICA PALEONTOLÓGICA}

Classe ECHINOIDEA Leske, 1778

Superordem STIRODONTA Jackson, 1912

Ordem CALYCINA Gregory, 1900

Família SALENIIDAE Agassiz, 1838

Subfamília SALENIINAE Agassiz, 1838

Tribo HOLOSALENIINI Smith \& Wright, 1990

Holosalenia Smith \& Wright, 1990
Holosalenia bahiensis sp. nov.

(Figuras 4 - 5)

Etimologia. O nome da espécie é em referência ao Estado da Bahia, onde a mesma foi coletada.

Holótipo. FPH-462-I, coletado na localidade Boipeba 3, Ilha de Boipeba.

Parátipos. 80 exemplares: FPH-449-I a FPH-456-I na localidade de Boipeba 2; FPH-460-I, FPH-461-I, FPH-463-I, FPH-464-I, FPH-467-I a FPH-503-I, FPH-507-I, FPH-508-I, MN 8251-I; MN 8252-I na localidade de Boipeba 3; FPH868-I; FPH-869-I na localidade de Boipeba 4; FPH-889-I; FPH-890-I na localidade de Tassimirim 1, todas na Ilha de Boipeba. Os fósseis FPH-870-I; FPH-871-I; FPH-873-I a FPH-876-I, coletados na localidade de Cangaíba 1; FPH879-I a FPH-882-I; FPH-885-I; FPH-886-I a FPH-888-I, coletados na localidade de Cangaíba 2, ambas na Ilha de Cangaíba.

Horizonte estratigráfico. Albiano superior do Membro Germânia, Formação Algodões, bacia de Camamu.

Diagnose. Disco apical arredondado, elevado em torno do periprocto e formado por placas lisas com as suturas pouco visíveis. Periprocto arredondado, com as bordas espessas; as depressões suturais entre as placas são pequenas, muitas vezes pouco profundas ou ausentes; região ambulacral estreita e quase completamente retilínea.

Diagnosis. The apical disc is circular in outline, elevated 


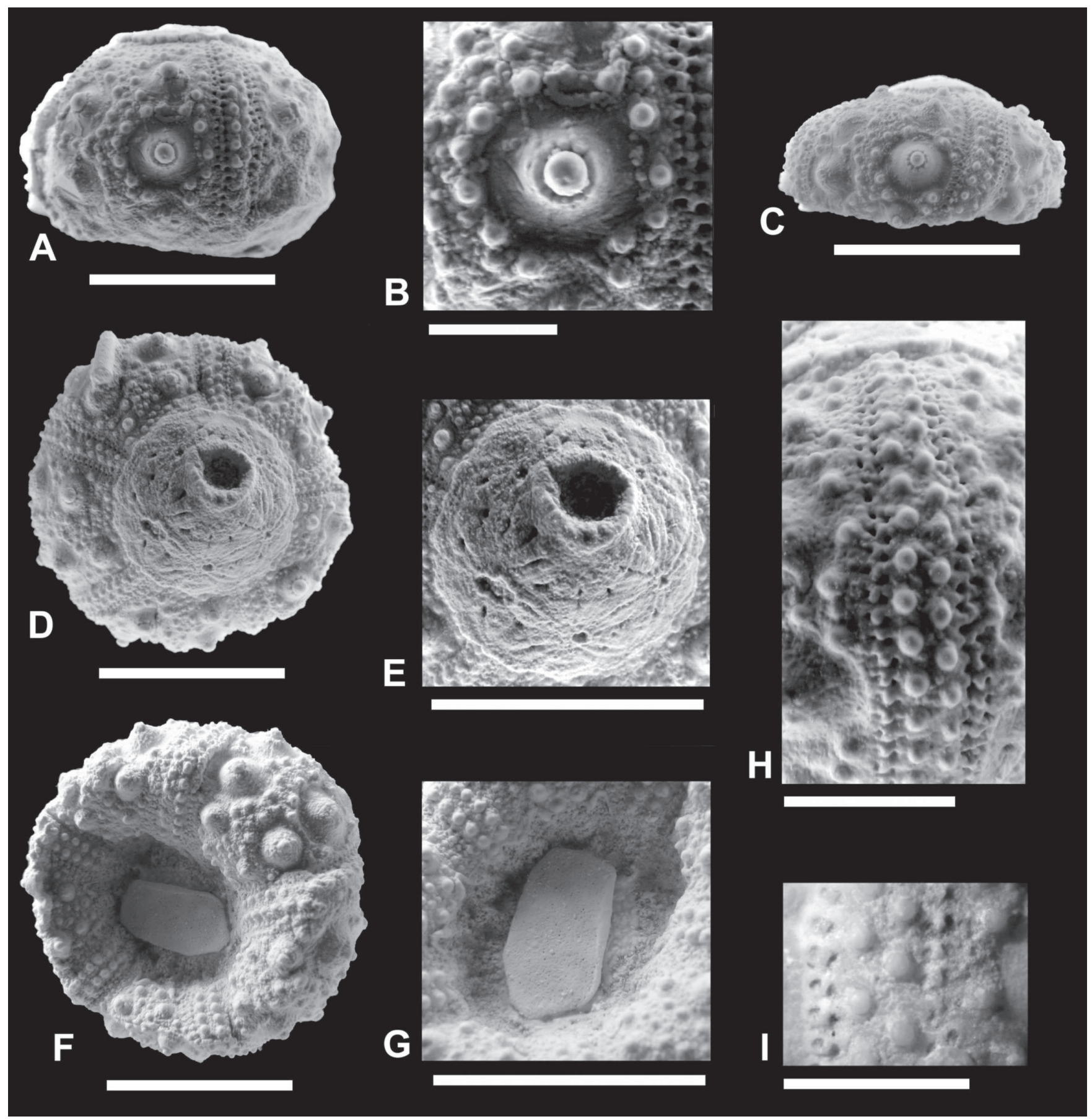

Figura 4. Holosalenia bahiensis sp.nov.: FPH-508-I, parátipo em vista lateral (A) e detalhe do tubérculo primário circundado pelo círculo escrobicular (B). Holótipo, FPH-462-I, em vistas lateral (C) e da região ambulacral (H) com detalhe da região ambulacral (I). Parátipo, FPH-461-I, em vista apical (D), com detalhe do disco apical (E) e em vista oral (F) com detalhe do peristoma (G). Escala: A-G, $=10 \mathrm{~mm}, \mathbf{H}-\mathrm{I}=5 \mathrm{~mm}$.

Figure 4. Holosalenia bahiensis n. sp.: paratype FPH-508-I in lateral view (A) and detail of the primary tubercle surrounded by scrobicular tubercles (B). Holotype, FPH-462-I, in lateral (C) and ambulacra (H) views with detail of the ambulacra (I). Paratype FPH461-I in apical view (D) and detail of the apical disc (E), oral view (F) with detail of the peristome (G). Scale bar: A-G, = $10 \mathrm{~mm}, \mathbf{H}-\mathbf{I}$ $=5 \mathrm{~mm}$.

around of the periproct and formed by smooth plates; the sutures among the apical plates are barely visible; the periproct is rounded with thick edges; the sutural pits among the plates are small, sometimes a little deep or absent; ambulacral region narrow and almost completely straight.

\section{Descrição}

Carapaça. Contorno circular com o peristômio levemente invaginado, medindo $19 \mathrm{~mm}$ de diâmetro e $11 \mathrm{~mm}$ de altura (Figura 4A). Disco apical elevado (Figura 4D). Âmbitus localizado abaixo da metade da altura da carapaça. O diâmetro das carapaças dos parátipos se situou entre 18 e $25 \mathrm{~mm}$ e a 


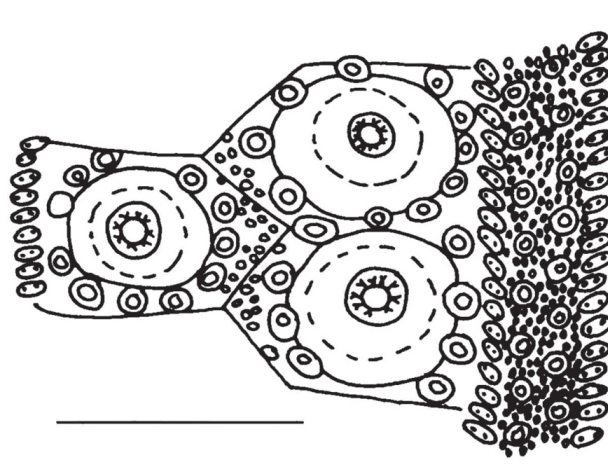

A

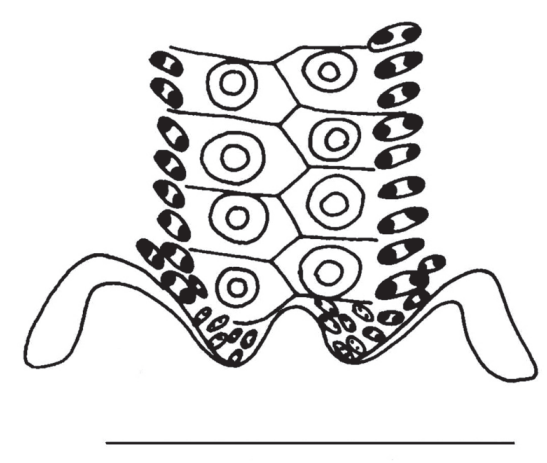

B

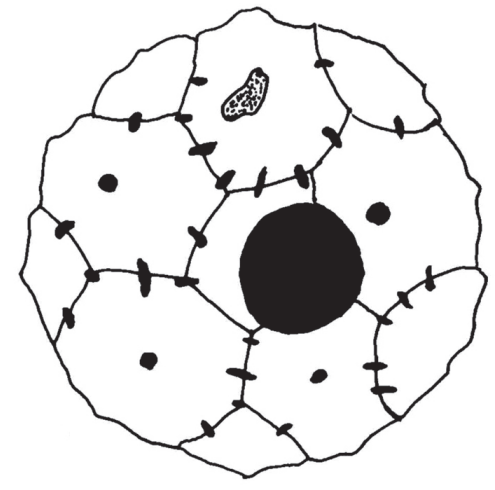

C

Figura 5. Desenho esquemático de Holosalenia bahiensis sp n.: A, placas interambulacrais e ambulacrais na altura do âmbitus; $\mathbf{B}$, região ambulacral próxima ao perístoma; $\mathbf{C}$, placas do disco apical. Escalas: $\mathbf{A}=2 \mathrm{~mm} ; \mathbf{B}=1 \mathrm{~mm} ; \mathbf{C}=5 \mathrm{~mm}$.

Figure 5. Drawings of Holosalenia bahiensis sp.n: A, interambulacral and ambulacral plates on the ambitus; $\mathbf{B}$, view of ambulacral area next to the peristoma; $\mathbf{C}$, apical disc plates. Scales bars: $\mathbf{A}=2 \mathrm{~mm} ; \mathbf{B}=1 \mathrm{~mm} ; \mathbf{C}=5 \mathrm{~mm}$.

altura entre 13 e $14 \mathrm{~mm}$ estando boa parte destas quebrada, amassada ou incrustada. Na região interambulacral do holótipo, foram observadas cinco placas na mesma fileira enquanto nos parátipos este número variou entre cinco e sete.

Região apical. Disco apical circular e elevado, com aproximadamente $50 \%$ do diâmetro da carapaça apresentando placas lisas, isto é, sem ornamentação, com 27 depressões suturais pouco profundas (Figura 4D, E). Os contatos entre as placas quase não são visíveis. Placas oculares subtriangulares com duas concavidades no bordo externo e com o bordo interno arredondado. Placas genitais sublosangulares com a abertura do poro próxima ao centro de cada placa. O madreporito possui formato irregular e está situado na placa genital 2. O periprocto é arredondado e não muito grande, com as bordas reforçadas medindo 2,0 mm de diâmetro (Figura 5C).

Região ambulacral. Estreita e quase retilínea, com duas fileiras de tubérculos primários não perfurados intercalados. Ao redor destes tubérculos podem ser observados diversos grânulos menores. A largura deste ambulacro na região próxima ao âmbitus é de $2,5 \mathrm{~mm}$. Foram contados 40 pares de poros e 21 tubérculos primários em uma coluna. As partições interporíferas são desenvolvidas (Figura 4H,I e 5B).

Região interambulacral. Medindo $7,5 \mathrm{~mm}$ na altura do âmbitus, com cinco placas em cada coluna. Cada uma destas placas possui um tubérculo primário com plataforma levemente crenulada, mamelão não perfurado e auréola grande. Entretanto aqueles tubérculos imediatos ao disco apical possuem as auréolas ligeiramente menores que as demais. Circundando cada uma das auréolas destes tubérculos, podem ser encontrados de 10 a 12 tubérculos escrobiculares, inclusive nas regiões adradiais de cada placa (Figura 4B). Na parte central da região interambulacral existem grânulos dispostos entre as regiões de tubérculos escrobiculares dando um aspecto de ziguezague na sutura interna das placas interambulacrais (Figura 5A).
Peristoma. É relativamente pouco invaginado, com o tamanho de aproximadamente $50 \%$ do diâmetro da carapaça. Podem ser observadas próximas ao perístoma fendas branquiais com $1 \mathrm{~mm}$ de comprimento com projeções calcárias (Figura 5B). Distribuição estratigráfica e geográfica. Espécie encontrada no Albiano superior do Membro Germânia da Formação Algodões, bacia de Camamu, nas ilhas de Boipeba e Cangaíba, bacia de Camamu, litoral centro-sul do Estado da Bahia.

\section{DISCUSSÃO}

Os exemplares fósseis coletados pelos autores na bacia de Camamu foram referidos para o gênero Holosalenia Smith \& Wright, por apresentarem as seguintes características que os separam dos demais gêneros de Holosaleniini Smith \& Wright, 1990: círculo escrobicular completo em volta dos tubérculos primários formado por 10 a 12 tubérculos contínuos; carapaças altas; discos apicais pequenos nos quais as depressões nas suturas triplas são pobremente desenvolvidas ou ausentes; tubérculos ambulacrais primários não contínuos e envolvidos por seu próprio anel de pequenos tubérculos; e gonoporos grandes.

As espécies de Holosalenia conhecidas do Cretáceo até o momento foram registradas para o Cretáceo Superior (Cenomaniano ao Campaniano/Maastrichtiano) da Europa, norte da África e Oriente Médio. Holosalenia bahiensis sp. nov. do Albiano superior da Formação Algodões, pode ser diferenciada de outros holosaleniídeos com base nas características descritas a seguir.

Holosalenia bahiensis sp. nov. difere de H. ammonitorum (Bandel \& Geys, 1985), na estrutura do disco apical, que em $H$. ammonitorum é pentagonal e com grandes depressões suturais; na posição dos poros genitais que em $H$. ammonitorum estão localizados no centro das placas genitais; nas regiões interambulacrais que são relativamente largas e nas superfícies extra escrobiculares extremamente granuladas 
em H. ammonitorum. As espécies diferem também no tamanho dos tubérculos das regiões ambulacral e interambulacral que em $H$. ammonitorum são menores do que aqueles de $H$. bahiensis sp. nov.

Holosalenia bahiensis sp. nov. difere de Holosalenia batnensis (Peron \& Gauthier, 1879) nos seguintes aspectos: na estrutura das placas do disco apical, onde em $H$. batnensis as placas são granuladas, as suturas triplas são grandes e as suturas entre as placas são claramente visíveis. A placa genital 2 ou madreporita mostra uma depressão porífera retangular e granulada, que ocupa $70 \%$ desta placa; $H$. batnensis possui ainda a região ambulacral marcadamente sinuosa, enquanto que $H$. bahiensis sp. nov., possui a região ambulacral quase retilínea. As duas espécies diferem também no número de tubérculos escrobiculares na região interradial, que em $H$. batnensis são 17 tubérculos formando um anel ao redor de cada tubérculo primário, enquanto em $H$. bahiensis sp.n. formam um anel com 10 a 12 tubérculos.

Holosalenia bahiensis sp. nov. é muito semelhante a Holosalenia hawkinsi (Checchia-Rispoli, 1948) mas difere na estrutura do disco apical, o qual em H. hawkinsi possui suturas e depressões bem marcadas. Holosalenia hawkinsi apresenta sempre um maior número de tubérculos primários (seis a sete) nas séries interradiais e nunca cinco como em $H$. bahiensis sp. nov.

Holosalenia somaliensis (Hawkins, 1935) difere da espécie nova principalmente, por apresentar as placas do disco apical, com as suturas bem demarcadas.

\section{Paleoecologia}

A carapaça globular de Holosalenia bahiensis sp. nov. aliada à ausência de pódios respiratórios especializados na região aboral e ao peristoma levemente côncavo, parecem indicar que esta espécie teria vivido em um ambiente formado por substrato mole, longe da ação das ondas, onde teria se movimentado lentamente pastando sobre as algas ou a procura de alimento junto aos detritos orgânicos misturados ao sedimento. Ambiente semelhante foi observado por Smith (1995) para Salenia nutrix Perón \& Gauthier, que possui carapaça globular com o formato próximo a H. bahiensis sp. nov.

Em alguns afloramentos da Formação Algodões, $H$. bahiensis sp. nov. foi encontrada associada ao equinóide Tetragramma malbosi Agassiz \& Desor. Na bacia de SergipeAlagoas (Sergipe), outro saleniideo, Leptosalenia sergipensis (White), de carapaça muito parecida a H. bahiensis sp. nov., porém mais baixa, também foi coletado em afloramentos datados como Albiano e onde T. malbosi também foi assinalado. Aparentemente, os salenídeos $H$. bahiensis e $L$. sergipensis ocuparam habitat semelhante nas duas bacias. Entretanto, a carapaça mais baixa de L. sergipensis denota uma maior exposição dos pódios, que neste grupo teriam também função respiratória, característica relacionada à ambientes mais rasos e oxigenados (Smith, 1995). Desta forma, embora as duas espécies de salenídeos tenham tido carapaças muito semelhantes, a diferença de altura e o formato mais elevado das placas do periprocto podem ter possibilitado $H$. bahiensis sp. nov. habitar ambientes mais profundos, menos agitados e, consequentemente, com menor teor de oxigênio dissolvido, do que L sergipensis na bacia de Sergipe-Alagoas (Manso, 2003).

\section{CONCLUSÕES}

Holosalenia bahiensis sp. nov. é considerada aqui como uma nova espécie, em virtude do conjunto de características apresentado: sistema apical arredondado e liso; periprocto arredondado, elevado e com as bordas espessas; suturas triplas entre as placas apicais pequenas ou ausentes; região ambulacral estreita e quase totalmente retilínea, que a diferencia das demais espécies deste gênero. Esta espécie teria vivido em um ambiente lagunar e/ou profundo devido às características de sua carapaça. Holosalenia bahiensis sp. nov. é a primeira espécie do gênero Holosalenia a ser descrita para a América do Sul assim como para o Albiano.

\section{AGRADECIMENTOS}

A Edilma de J. Andrade, Aurivonele F. Lima (in memorian) e Murilo Marchioro (UFS) pelo auxílio nos trabalhos de campo; a R. Souza-Lima e Jean M. A. M. Nunes pelas fotografias dos exemplares; e aos consultores anônimos pela revisão do manuscrito. Este trabalho é dedicado à memória de Aurivonele F. Lima.

\section{REFERÊNCIAS}

Agassiz, L.1838. Monographie d'Echinodermes vivans et fossils. Première monographie: Des Salénies. Neuchâtel, 32 p.

Andrade, E. J.; Souza-Lima, W. \& Leite, O. R. 2006. Macrofauna do Membro Quiepe, bacia de Camamu, Bahia, Brasil. In: ENCONTRO REGIONAL DA SOCIEDADE BRASILEIRA DE PALEONTOLOGIA, PALEO 2006. Resumos, Sobral, UVA, p. 4.

Andrade, E. J.; Seeling, J.; Bengtson, P.; Souza-Lima, W. 2004. The Bivalve Neithea from the Cretaceus of Brazil. Journal of South American Earth Sciences, 17:25-38.

Bandel, K. \& Geys, J. 1985. Regular echinoids in the Upper Cretaceous of the Hashemite Kingdom of Jordan. Annales de la Societé Géologique du Nord, 104:97-115.

Bengtson, P. 1983. The Cenomanian-Coniacian of Sergipe Basin, Brazil. Fossils and Strata, 12:1-78.

Berthou, P.Y.; Brito, I.M.; Campos, D.A. \& Depeche, F. 1996. Le Bassin de Recôncavo Sud-Camamu: Précisions et Données Nouvelles sur Stratigraphie et le Paléoenvironnement de la Partie Súpérieure de la Formation Taipu-Mirim et sur la Formation Algodões. Implications Paléogéographiques. Anais da Academia Brasileira de Ciências, 68(2):175-186.

Brito, I.M. 1964. Equinóides cretácicos do Estado da Bahia. Escola de Geologia, Universidade Federal da Bahia, 11 p. (Publicações Avulsas 1)

Brito, I.M. 1967. Novas ocorrências de Lamelibrânquios no Cretáceo da Bahia. Notas Preliminares e Estudos, 139:1-9.

Brito, I.M. 1980. Os equinóides fósseis do Brasil I. Os endocíclicos. Anais da Academia Brasileira de Ciências, 52(3):569-590.

Brito I.M. 1981. Os Equinóides fósseis do Brasil III. Espatangóides, exceto Hemiasteridae. Anais da Academia Brasileira de Ciências, 
53(3):569-578.

Checchia-Rispoli, G. 1948. "Salenia hawkinsi" nuovo echinide del Cenomaniano della Somalia. Rendiconti dell Academia Nazionale dei Lincei, 8(4):169-172.

Gregory, J. H. 1900. The Echinoidea. In: E. R. Lankester (ed.) A Treatise on Zoology. Part III, the Echinodermata, London Press, p. 282-332.

Hawkins, H.L. 1935. Some Cretaceous Echinoidea. Geology and Paleontology of British Somaliland, 2:47-56.

Jackson, R.T. 1912. Phylogeny of the Echini, with a revision of Paleozoic species. Memoirs of the Boston Society of Natural History, 7:1-490.

Leske, N.G. 1778. Jacobi Theodori Klein naturalis dispositio. Echinodermatum.Addimenta ad Kleinii dispositionem Echinodermatum. Lipis, Officina Gleditschiana. 279 p.

Manso, C.L.C. 2003. Paleoecologia, Paleobiogeografia e sistemática dos equinóides do Aptiano-Albiano (Cretáceo) do Brasil. Programa de Pós-graduação em Geologia, Universidade Federal da Bahia, Tese de Doutorado, 206 p.

Maury, C.J. 1925. Fósseis Terciários do Brasil, com descrição de novas formas cretáceas. Serviço Geológico e Mineralógico, Monografia, 4:1-665.

Netto, A.S.T.; Filho, J. R. W.; Feijó, F. J. 1995. Bacias de Jacuípe, Camamu e Almada. Boletim de Geociencias da Petrobras, 8(1):173-184.

Peron, P.A. \& Gauthier, V. 1879. Étage Cenomanien. In: G. Cotteau; P. A. Peron \& V. Gauthier (eds.) Échinides fossiles de l'Algerie, Masson, p. 145-234.

Santos, M.E.C. M. 1958. Ocorrência de equinóides fósseis no Estado da Bahia. Rio de Janeiro, Departamento Nacional de Produção Mineral, Divisão de Geologia e Mineralogia, 5 p. (Boletim 104)

Smith, A.B. 1995. Late Campanian-Maastrichtian echinoids from the United Arab Emirates-Oman border region. Bulletin of the Natural History Museum, 51(2):121-240.

Smith, A.B. \& Bengtson, P. 1991. Cretaceous echinoids from northeastern Brazil. Fossils and Strata, 31:1-88.

Smith, A.B. \& Wright, C.W. 1990. British Cretaceous Echinoids. Part 2, Echinothurioida, Diadematoida and Stirodonta (1, Calycina). Monograph of the Palaeontographical Society, 143(583):101-198.

Received in May, 2006; accepted in March, 2007. 